\title{
Helminth Control: In Vitro Anthelmintic and Larvicidal Activities of Solanum surattense Against Fasciola gigantica (Sporocyst, Redia, and Cercaria) Larvae
}

\author{
Pradeep Kumar $^{1 * \mathbb{D}}$ \\ 'Department of Zoology, S.G.N. Govt. P.G. College, Muhammadabad Gohna, Mau, Uttar Pradesh, India
}

\begin{abstract}
Introduction: Liver flukes (Fasciola species) are parasitic helminths that cause fascioliasis in cattle and humans. The Fasciola species (F. hepatica and F. gigantica) have complicated life cycles in the host snails and mammals. The cattle and human population get infected after ingestion of contaminated miracidium stages of Fasciola through aquatic plants or contaminated water. The developmental stages of liver flukes can be discontinued by terminating larval stages such as sporocyst, redia, and cercaria in vivo or by killing intermediate hosts. Synthetic anthelmintic compounds are highly effective but they cause adverse effects in the environment. Plant products are eco-friendly and safe which can be used in the control of parasitic helminths. Methods: In vitro anthelmintic activities of different preparations of Solanum surattense such as pulverized leaf products, extracts (ether, chloroform, methanol, acetone, and ethanol), and column purified fractions were assessed against sporocyst, redia, and cercaria larvae of $F$. gigantica. Different preparations of the $S$. surattense were assessed separately against Fasciola larva after 2 to 8 hours of exposure. These larvae, having up to 48-hour survivability, were kept in tap water at laboratory conditions.

Results: Larval mortality was observed after 2, 4, 6, and 8 hours of exposure for the calculation of $\mathrm{LC}_{50}$ value. Among all the organic extracts, the maximum larvicidal activity was observed in ethanol after 2 hours of exposure, the $\mathrm{LC}_{50}$ value against sporocyst, redia, and cercaria was reported to be $63.21,64.24$, and $63.54 \mathrm{mg} / \mathrm{mL}$, respectively. However, maximum activity was observed after 8 hours of exposure in column purified fractions, and the $\mathrm{LC}_{50}$ value against sporocyst, redia, and cercaria was reported to be $48.25,47.61$, and $44.15 \mathrm{mg} / \mathrm{mL}$, respectively.

Conclusion: Conclusively, the present research study indicates that $S$. surattense is a potent source of anthelmintic compounds which can be used for the control of sporocyst, redia, and cercaria larvae of $F$. gigantica.

Keywords: Liver fluke, Solanum surattense, Sporocyst, Redia, Cercaria, Fascioliasis
\end{abstract}

Received: November 3, 2020 , Accepted: December 9, 2020, ePublished: December 30, 2020

\section{Introduction}

Fascioliasis is a zoonotic disease among wild and household animals as well as humans, which is caused by trematode species of Fasciola (1-3). Fasciola hepatica and Fasciola gigantica are common liver flukes that cause fascioliasis $(4,5)$. The adult fluke (Fasciola species) produces infection in the liver of mammals especially cattle which feed on aquatic plants that are contaminated with infective-stage of metacercaria (6-8). Fascioliasis is listed as a neglected tropical disease by the World Health Organization (WHO) (8). The liver fluke is an important parasite for domesticated animals which causes major economic losses (9). The prevalence of Fasciola spp. infection is approximately 17 million in the human population worldwide $(8,10)$. The lymnaeid snails are secondary or intermediate hosts of Fasciola spp. which have an effective role in the distribution of liver flukes
(11). The species of F. gigantica is restricted to Asia and Africa $(1,12)$. The risk of fascioliasis and distributions is followed by the secondary host, which is the main factor that sustains in the endemic part of the world (13). The snail Lymnaea acuminata is a secondary host of F. gigantica $(14,15)$. This species of snail is a hermaphrodite in nature that inhabits freshwater ponds, pools, lakes, rivers, and low-lying submerged fields. The endemic zoonotic disease is very common among the bovine population of eastern Uttar Pradesh, India (16-20). The lifecycle of the Fasciola is very complex in the intermediate host (snail) and primary host (mammals, including humans). The eggs of the Fasciola can be seen in the host stool which embryonated in the water and each egg generates a single miracidium stage. This miracidium stage punctures the tegument layer of the host animals and causes infection. In digenetic trematodes, the development of the larva is 
a very complex process. It begins to develop in the host body and changes into miracidium. The miracidium stage changes into the sporocysts which are followed by asexual reproduction and convert into sporocyst, redia, and finally cercaria. The cercaria is a free-swimming larval stage of Fasciola spp. Therefore, it may be a basic approach to control fascioliasis by breaking the life cycle of Fasciola spp. through killing the larval stages in the host body. Synthetic anthelmintic/larvicidal drugs are useful and effective in the control of Fasciola larva, but they cause adverse effects in the environment. Currently, plant products are used in in vitro treatment of Fasciola larvae (sporocyst, redia, and cercaria) which may be a new tool for in vivo phytotherapy of the infected intermediate host snail. Sunita and Singh, (18) reported that the plant-derived active components are effective in in vivo phytotherapy of the F. gigantica larva in host snail. The present study aims to assess in vitro anthelmintic and larvicidal properties of S. surattense in the control of sporocyst, redia, and cercaria.

\section{Materials and Methods Collection of Host Snails and Fasciola Larvae}

The snail $L$. acuminata $(2.7 \pm 0.26 \mathrm{~cm}$ in length) was collected from a submerged field of the Muhammadabad Gohna, Mau Uttar Pradesh, India. The host snails were acclimatized for 72 hours in lab condition at $26^{\circ} \mathrm{C}$. Infected and non-infected snails were separated into two groups based on the morphological characteristics and cercarial shedding rate. The shells of infected snails were operated on and larvae of Fasciola were collected. After collection, sporocyst, redia, and cercaria larvae were poured into different Petri dishes containing $10 \mathrm{~mL}$ of tap water (18). The sporocyst, redia, and cercaria larvae, having up to 48-hour survivability, were kept in tap water in the lab conditions at $24-26^{\circ} \mathrm{C}$.

\section{Preparation of Plant Leaf Powder}

The leaf of the plant Solanum surattense was identified and collected from the college campus. The collected leaves were washed by distilled water, sun-dried for 4 to 5 days, and pulverized in a grinder. The powder was sieved with sterilized fine cloth mesh and used against sporocyst, redia, and cercaria.

\section{Organic Extraction of Leaf Powder}

In each extraction, $5 \mathrm{~g}$ of dried leaf powder of $S$. surattense was added separately to $500 \mathrm{~mL}$ of $97.8 \%$ ether, $98.5 \%$ chloroform, $97.4 \%$ methanol, $97.6 \%$ acetone, and $94.6 \%$ ethanol at lab conditions. After 48 hours, all the extracts were filtered by sterilized filter paper and the obtained extracts were evaporated in a vacuum machine. The extract from leaf powder of S. surattense yielded $345 \mathrm{mg}$ ethanol, $330 \mathrm{mg}$ chloroform, $335 \mathrm{mg}$ ether, and $325 \mathrm{mg}$ acetone. Then, extract residues were collected and used in in vitro treatment.

\section{Preparation of Column Purified Fractions}

In this study, $1 \mathrm{~L}$ of organic solvent (ethanol 94.6\%) was used for the preparations of column fractions of $S$. surattense leaf powder and it was subjected to silica gel (60-120 nm mesh size) column chromatography through a $5 \times 45 \mathrm{~cm}$ column cylinder. The fractions were collected in the conical flask and evaporated using a vacuum machine. Then, the remaining residue of the column purified was collected and used against larvae.

\section{In Vitro Anthelmintic Activity}

The leaf powder, various extracts, and column purified fractions of S. surattense were separately assessed against Fasciola larva using the method used by Sunita and Singh, (18). In six batches, 10 sporocysts, redia, and cercaria larvae were separately kept in Petri dishes which contained $10 \mathrm{~mL}$ of tap water. Different preparations of dried leaf powder, organic extracts, and column purified fractions were separately made in the Petri dishes which contained 10 sporocyst, redia, and cercaria larvae. The larval (sporocyst, redia, and cercaria) mortality was calculated after 2, 4, 6, and 8 hours of exposure. In each experimental setup, larval counting and observation were done with the help of a binocular microscope. The larval mortality (lethal concentration $=\mathrm{LC}_{50}$ value) at each concentration was calculated after 2, 4, 6, and 8 hours of exposure. The $\mathrm{LC}_{50}$, LCL (lower confidence limits), UCL (upper confidence limits), t-ratio, and slope values were calculated by POLO software (21).

\section{Results}

The in vitro anthelmintic and larvicidal activities of dried leaf powder, organic extracts (ether, chloroform, methanol, acetone, and ethanol), and column purified fractions of S. surattense against sporocyst, redia, and cercaria stages of $F$. gigantica were concentration and time-dependent from 2 hours up to 8 hours (Table 1). In vitro larvicidal activity of leaf powder was assessed against sporocyst, redia, and cercaria after 2 hours of exposure, and the $\mathrm{LC}_{50}$ value was found to be 70.23, 68.35, and $66.11 \mathrm{mg} / \mathrm{mL}$, respectively. Likewise, among all the organic extracts (ether, chloroform, methanol, acetone, and ethanol), the maximum activity was observed in ethanol extract after 2 hours of exposure, and the $\mathrm{LC}_{50}$ value against sporocyst, redia, and cercaria was reported to be $63.21,64.24$, and, $63.54 \mathrm{mg} / \mathrm{mL}$, respectively (Table $1)$. The highest activity was observed after 8 hours of exposure in column purified fraction, and the $\mathrm{LC}_{50}$ value against sporocyst, redia, and cercaria was found to be $48.25,47.61$, and $44.15 \mathrm{mg} / \mathrm{mL}$, respectively. However, the minimum activity was observed in methanol extract after 2 hours of exposure, and the $\mathrm{LC}_{50}$ value against sporocyst, redia, and cercaria was found to be $69.45,67.65$, and 65.96 


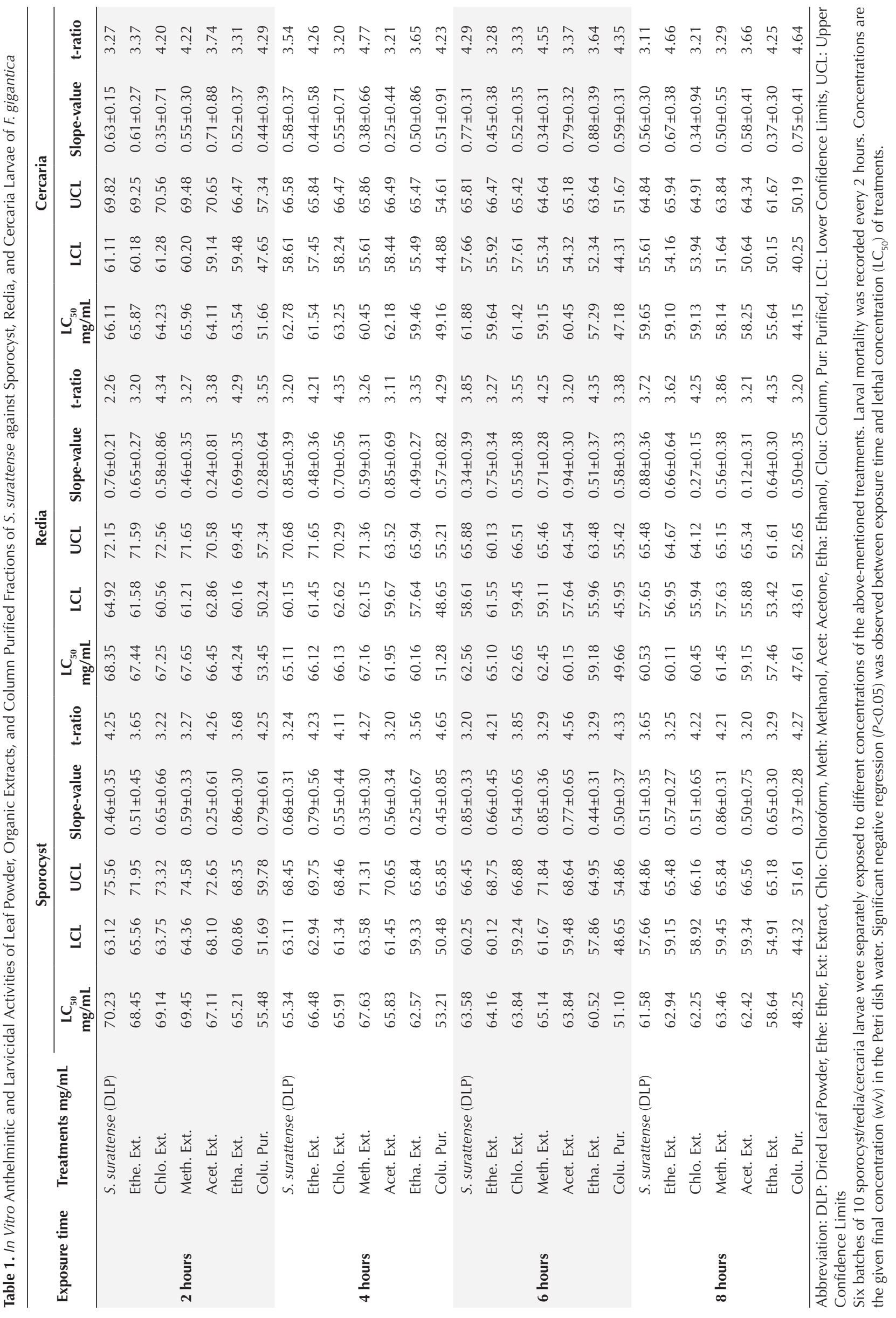

Int J Med Parasitol Epidemiol Sci Volume 1, Number 4, 2020 
$\mathrm{mg} / \mathrm{mL}$, respectively.

The separate estimation the $\mathrm{LC}_{50}$ and slope-values was based on six replicates of the experiment which is found within the $95 \%$ confidence limit of the lethal concentration of the various preparations. The value of t-ratio was greater than 1.96 , which verifies significant anthelmintic and larvicidal activities (Table 1).

\section{Discussion}

The results demonstrate that the leaf powder of $S$. surattense is a vigorous source of anthelmintic compounds. The results of the study revealed that anthelmintic and larvicidal compounds of $S$. surattense are present in the leaf, which is soluble in organic solvents and causes mortality in sporocyst, redia, and cercaria larvae of $F$. gigantica. The efficacy $\left(\mathrm{LC}_{50}\right)$ of the various preparations of the $S$. surattense was concentration and time-dependent against sporocyst, redia, and cercaria. The efficacy of different preparations of $S$. surattense may possibly be due to the fact that various active phytochemicals are accumulated in the larval body which gradually increases with the increase of exposure time. It bound to the active site of the enzymes and caused larval mortality. It was indicated that the cuticle layers of the larvae permitted the penetration of the active components into the body that causes mortality. Mahesh Kumar et al (22) reported that leaf extract of $S$. surattense is more effective against Culex quinquefasciatus larvae. The ethanolic and aqueous extracts of the fruit powder of the S. surattense have anthelmintic activity against earthworms Pheretima posthuma (23). The maximum efficacy was observed in ethanolic extract among other extracts which indicates that the active larvicidal compounds of $S$. surattense are soluble in the ethanolic solvent (Table 1).

In vitro larvicidal efficacy of $S$. surattense is time and concentration-dependent which may be due to the fact that active components are gradually dissolved in tap water and then diffuse in the larval body which causes larval mortality with the increase in exposure time. Barik et al (24) indicated that the aqueous extract of the fruit of the S. surattense is a source of anthelmintic compounds. The leaf extract of S. surattense contains phytochemicals such as flavonoids and their glycosides (25), saponin (26), sterols (27), several alkaloids (28), tannins, and gums (29). The aqueous, ethanolic, and hydroethanolic extracts of the S. surattense have anthelmintic activity (30). The methanolic extract of the S. surattense has antibacterial properties against Gram-positive bacteria Streptococcus aureus and Bacillus subtilis at 50,75 , and $100 \mu \mathrm{g} / \mathrm{mL}$ concentrations (31). Bahuguna et al (32) investigated antiulcer activity of $S$. surattense using aqueous alcohol, petroleum ether, and chloroform extracts based on parameters such as total acidity, $\mathrm{pH}$, free acidity, and ulcer index. Various products of S. surattense are also used in the treatment of the cold, insomnia, worms (33), and enlargement of the liver for their laxative, aphrodisiac $(34,35)$, anti-nociceptive, anti-fungal, and molluscicidal properties $(36,37)$. Hussein Ayoub and Yankov (38) reported that tannin is a potent molluscicidal component. The extract of $S$. surattense has anti-cancerous activities which may be due to the presence of flavonoids such as quercetin, apigenin, luteolin, and fisetin which are known to be vigorous inhibitors of cancer cell growth (39). The ethanolic extracts of S. surattense remarkably reduced parasitemia in infected mice (40). The slope-values clearly show that the minimum concentration of active components increases with the increase of exposure period which causes mortality in Fasciola larvae (Table 1). The value of t-ratio was greater than 1.96 which shows significant regressions.

\section{Conclusion}

This study established that medicinal plant S. surattense and its dried leaf powder, different organic extracts (ether, chloroform, methanol, acetone, and ethanol), and column purified fractions killed the sporocyst, redia, and cercaria larvae of $F$. gigantica. This study indicates that the active component of the $S$. surattense can be used in in vivo phytotherapy of the infected host snail. The plant-derived active components are easily available, biodegradable, safe, and eco-friendly for other non-target aquatic organisms. It may be one of the new approaches and tools for in vivo treatment of sporocyst, redia, and cercaria larvae without killing the intermediate host snail for the control of fascioliasis.

\section{Conflict of Interests}

The authors declare that they have no conflict of interests.

\section{Ethical Issues}

In this study, ethical considerations have been fully observed.

\section{References}

1. Mas-Coma S, Valero MA, Bargues MD. Climate change effects on trematodiases, with emphasis on zoonotic fascioliasis and schistosomiasis. Vet Parasitol. 2009;163(4):264-280. doi:10.1016/j.vetpar.2009.03.024

2. Hambal M, Ayuni R, Vanda H, Amiruddin A, Athaillah F. Occurrence of Fasciola gigantica and Paramphistomum spp infection in Aceh cattle. E3S Web Conf. 2020;151:01025. doi:10.1051/e3sconf/202015101025 bebin in ketabe

3. Vishwakarma AK, Kumar P. In vivo anthelmintic activity of medicinal plant Asparagus racemosus against larva of Fasciola gigantica. Res J Agric Sci. 2021;12(2):675-680.

4. Le TH, De NV, Agatsuma T, et al. Molecular confirmation that Fasciola gigantica can undertake aberrant migrations in human hosts. J Clin Microbiol. 2007;45(2):648-650. doi:10.1128/ jcm.01151-06

5. Admassu B, Shite A, Kinfe G. A review on bovine fasciolosis. 
Eur J Biol Sci. 2015;7(3):139-146. doi:10.5829/idosi. ejbs.2015.7.03.9558

6. Kumar P, Singh DK. In vitro anthelmintic activity of Allium sativum, Ferula asafoetida, Syzygium aromaticum and their active components against Fasciola gigantica. J Biol Earth Sci. 2014;4(1):B57-B65.

7. Kumar P, Sunita K, Singh DK. In vitro activity of different phytochemicals in binary combinations against Fasciola gigantica. Curr Life Sci. 2016;2(3):58-63. doi:10.5281/ zenodo.56405

8. Mas-Coma S, Bargues MD, Valero MA. Human fascioliasis infection sources, their diversity, incidence factors, analytical methods and prevention measures. Parasitology. 2018;145(13):1665-1699. doi:10.1017/s0031182018000914

9. McManus DP. Recent progress in the development of liver fluke and blood fluke vaccines. Vaccines (Basel). 2020;8(3):553. doi:10.3390/vaccines8030553

10. Haridwal S, Malatji MP, Mukaratirwa S. Morphological and molecular characterization of Fasciola hepatica and Fasciola gigantica phenotypes from co-endemic localities in Mpumalanga and KwaZulu-Natal provinces of South Africa. Food Waterborne Parasitol. 2021;22:e00114. doi:10.1016/j. fawpar.2021.e00114

11. Robinson MW, Dalton JP. Zoonotic helminth infections with particular emphasis on fasciolosis and other trematodiases. Philos Trans R Soc Lond B Biol Sci. 2009;364(1530):2763-2776. doi:10.1098/rstb.2009.0089

12. Lotfy WM, Hillyer GV. Fasciola species in Egypt. Exp Pathol Parasitol. 2003;6(11):9-22.

13. Rondelaud D, Hourdin P, Vignoles P, Dreyfuss G. The contamination of wild watercress with Fasciola hepatica in central France depends on the ability of several lymnaeid snails to migrate upstream towards the beds. Parasitol Res. 2005;95(5):305-309. doi:10.1007/s00436-004-1283-5

14. Osman EA, Mohamed EM, Abu Elreesh BI, Elegami AA. Molluscicidal activity of Cobretum glutinosum. Int J Mol Med Adv Sci. 2007;3(4):151-154.

15. Kumar P, Singh VK, Singh DK. Bait formulations of molluscicides and their effects on biochemical changes in the ovotestis of snail Lymnaea acuminata (Mollusca; Gastropoda:Lymnaeidae). Rev Inst Med Trop Sao Paulo. 2011;53(5):271-275. doi:10.1590/ s0036-46652011000500006

16. Singh O, Agarwal RA. Toxicity of certain pesticides to two economic species of snails in northern India. J Econ Entomol. 1981;74(5):568-571. doi:10.1093/jee/74.5.568

17. Kumar P, Singh DK. Molluscicidal activity of Ferula asafoetida, Syzygium aromaticum and Carum carvi and their active components against the snail Lymnaea acuminata. Chemosphere. 2006;63(9):1568-1574. doi:10.1016/j.chemosphere.2005.08.071

18. Sunita K, Singh DK. Fascioliasis control: in vivo and in vitro phytotherapy of vector snail to kill Fasciola larva. J Parasitol Res. 2011;2011:240807. doi:10.1155/2011/240807

19. Kumar P, Sunita K, Singh DK. Molluscicidal activity of different organic root extract of Potentilla fulgens against liver fluke vector snail Indoplanorbis exustus. Asian J Anim Sci. 2018;12(1):30-35. doi:10.3923/ajas.2018.30.35

20. Kumar P, Sunita K, Singh RN, Singh DK. Fascioliasis: a fluke infection is food-borne parasitic zoonosis and control their vectors. Int J Biol Med Res. 2020;11(1):6982-6989.

21. Robertson JL, Russell RM, Preisler HK, Savin NE. Bioassays with Arthropods. 2nd ed. Boca Raton: CRC Press; 2007:1-224.

22. Mahesh Kumar P, Murugan K, Kovendan K, et al. Mosquitocidal activity of Solanum xanthocarpum fruit extract and copepod Mesocyclops thermocyclopoides for the control of dengue vector Aedes aegypti. Parasitol Res. 2012;111(2):609-618. doi:10.1007/ s00436-012-2876-Z

23. Nayak BS, Jena PK, Sahu NP, Nayak UK, Patro KB. Comparative study of anthelmintic activity between aqueous and ethanolic extract of Solanum surattense Linn. Int J Pharm Pharm Sci. 2009;1(1):103-107.

24. Barik CS, Parida N, Sahu D, Sahoo AR. Solanum surattense: evaluation of anthelmintic activity. J Pharm Adv Res. 2018;1(5):240-246.

25. Dubey P, Gupta PC. A new flavonol glycoside from the flowers of Solanum xanthocarpum. Phytochemistry. 1978;17(12):2138. doi:10.1016/S0031-9422(00)893024

26. Tupkari SV, Saoji AN, Deshmukh VK. Phytochemical study of Solanum xanthocarpum. Planta Med. 1972;22(2):184-187. doi:10.1055/s-0028-1099601

27. Kusano G, Beisler J, Sato Y. Steroidal constituents of Solanum xanthocarpum. Phytochemistry. 1973;12(2):397-401.

doi:10.1016/00319422(73) $80027-5$

28. Siddiqui S, Faizi S, Siddiqui BS. Studies in the chemical constituents of the fresh berries of Solanum xanthocarpus Schrad. and Wendle. J Chem Soc Pak. 1983;5(2):99-102.

29. Sheeba E. Antibacterial activity of Solanum surattense Burm. F. Kathmandu Univ J Sci Eng Technol. 2010;6(1):1-4.

30. Pardhi P, Jain AP, Ganeshpurkar A, Rai G. Antimicrobial, anti-oxidant and anthelmintic activity of crude extract of Solanum xanthocarpum. Pharmacogn J. 2010;2(11):400-404. doi:10.1016/s09753575(10)80022-7

31. Patil S, Joshi V, Sutar P, Sambrekar S. Screening of whole plant extract of Solanum surattense for antibacterial activity. Int J Pharm Sci. 2009;1(1):110114.

32. Bahuguna Y, Juyal V, Gusain K. Pharmacological evaluation of Solanum Surattense leaves for antiulcer activity. J Pharm Res. 2008;2:253-259.

33. Mathur D, Agrawal RC. Withania coagulans: a review on the morphological and pharmacological properties of the shrub. World J Sci Technol. 2011;1(10):30-37.

34. Kiritikar KR, Basu BD. Indian Medicinal Plant. 2nd ed. Dehradun: Bishen Singh Mahendra Pal Singh; 2005:1759-1762.

35. Gupta RK, Hussain T, Panigrahi G, et al. Hepatoprotective effect of Solanum xanthocarpum fruit extract against $\mathrm{CCl} 4$ induced acute liver toxicity in experimental animals. Asian Pac J Trop Med. 2011;4(12):964-968. doi:10.1016/s19957645(11)60227-7

36. Bhutani KK, Paul AT, Fayad W, Linder S. Apoptosis inducing activity of steroidal constituents from Solanum xanthocarpum and Asparagus racemosus. 
Phytomedicine. 2010;17(10):789-793. doi:10.1016/j. phymed.2010.01.017

37. Kumar P. Molluscicidal efficacy of medicinal plant Solanum surattense against Fasciola vector snail, Lymnaea acuminata. Int J Biol Innov. 2021;3(1):120-126. doi:10.46505/ijbi.2021.3110

38. Hussein Ayoub SM, Yankov LK. The molluscicidal factor of tannin-bearing plants. Int J Crude Drug Res. 1986;24(1):1618. doi:10.3109/13880208609060881

39. Kumar S, Pandey AK. Medicinal attributes of Solanum xanthocarpum fruit consumed by several tribal communities as food: an in vitro antioxidant, anticancer and anti HIV perspective. BMC Complement Altern Med. 2014;14:112. doi:10.1186/1472-6882-14-112

40. Garedaghi Y, Khaki A. Evaluation of the effectiveness of ethanolic extract of Solanum surattense against Plasmodium berghei in comparison with chloroquine in Sourian mice using in vivo tests. Crescent J Med Biol Sci. 2014;1(3):7679.

(C) 2020 The Author(s); This is an open-access article distributed under the terms of the Creative Commons Attribution License (http:// creativecommons.org/licenses/by/4.0), which permits unrestricted use, distribution, and reproduction in any medium, provided the original work is properly cited. 